\title{
Erratum to: Jay Wright Forrester (1918-2016): His Contribution to the Concept of Overshoot in Socioeconomic Systems
}

\author{
Ugo Bardi ${ }^{1}$
}

Published online: 9 December 2016

(C) Springer International Publishing Switzerland 2016

\section{Erratum to: Biophys Econ Resour Qual (2016)}

\section{1:12 DOI 10.1007/s41247-016-0014-8}

The original version of this article unfortunately contained a mistake. "Jay Write Forrester" should read as "Jay Wright Forrester" in the title and throughout the article. The original article was corrected. 